\title{
Peningkatan Mutu Prestasi \& Minat Bakat SMTPI Jemaat Bethesda melalui aplikasi Microsoft Power Point
}

\author{
Joanna Cristy Patty*1, Dennis Rian Lopulissa ${ }^{2}$, Imanuel Lorenzo Pattiasina ${ }^{3}$ \\ ${ }^{3}$ Program Studi Teknik Informatika, Fakultas Ilmu Komputer, Universitas Kristen Indonesia Maluku \\ *e-mail: cristyjoanna18@gmail.com ${ }^{1}$, lopulissadennis@gmail.com², imanuelpattiasina74@gmail.com ${ }^{3}$
}

\begin{abstract}
Education accompanied by creativity is an inseparable part. Through education and creativity, it is hoped that it can change the mindset of humans to be wider and have quality behavior. In addition, education is also often referred to as the process of educating. The educational process is generally carried out in schools, institutes, academies, high schools, universities and so on. The development of Information and Communication Technology is currently experiencing very rapid changes and developments. Many new innovations in various fields have begun to be developed and involved in technological incubators such as business, industry, agriculture, health, and without exception education in particular, in providing learning process media. The world of education is also accompanied by the importance of creativity from students, so the author feels to increase student creativity with Power Point training as a form of creative presentation in schools whose activities are carried out at SMTPI Bethesda.
\end{abstract}

Keywords: Education, Microsoft Power Point, SMTPI Bethesda, Creativity.

\begin{abstract}
Abstrak
Pendidikan diiringi dengan kreatifitas merupakan salah satu bagian yang tidak dapat dipisahkan. Melalui Pendidikan dan kreatifitasnya diharapkan dapat merubah pola pikir manusia menjadi lebih luas dan tingkah laku yang berkulitas. Selain itu Pendidikan juga sering disebut proses mendidik. Proses mendidik tersebut secara umum biasanya dilakukan di sekolah, institut, akademi, sekolah tinggi, universitas dan lain sebagainya. Perkembangan Teknologi Informasi dan Komunikasi saat ini mengalami perubahan dan perkembangan yang sangat pesat. Banyak inovasi-inovasi baru diberbagai bidang mulai dikembangkan dan terlibat dalam inkubator teknologi seperti bisnis, industri, pertanian, kesehatan, dan tanpa terkecuali pendidikan khususnya, dalam penyedia media proses pembelajaran. Dunia Pendidikan juga diiringi dengan Pentingnya kreatifitas dari Pada Pelajar, sehingga penulis merasa untuk meningkatkan kreatifitas pelajar dengan pelatihan Power Point sebagai bentuk kreatifitas presentasi di sekolah yang kegiatannya dilaksanakan pada SMTPI Bethesda.
\end{abstract}

Kata kunci: Pendidikan, Power Point, SMTPI Bethesda, Kreatifitas.

\section{PENDAHULUAN}

Seiring dengan perkembangan zaman, tuntutan terhadap kemajuan ilmu pengetahuan dan teknologi suatu bangsa tentu tidak terlepas dari keberhasilan proses pembelajaran di negara tersebut. Tahapan perubahan diharapkan mampu membawa bangsa kearah kemajuan yang lebih tinggi. Tingkat penguasaan ilmu dan teknologi tidak hanya dilakukan pada Pendidikan formal, namun juga dapat dilakukan melalui Pendidikan nonformal.

Pada Undang-undang dasar No 20 Tahun 2003 tentang system Pendidikan nasional mengemukakan bahwa, Pendidikan itu usaha sadar dan terencana untuk mewujudkan suasana pelajar dan proses pembelajaran supaya siswa dapat aktif mengembangkan pola pikir dirinya serta keterampilan yang dimilikinya dan Pendidikan merupakan bentuk usaha untuk mewujudkan sistematis pembelajaran yang aktif dan efisien sehingga dijadikan sebagai wadah untuk mengembangkan bakat, menggali potensi diri, dan mengetahui jati diri dalam bermasyarakat (Muhamad Sholahudin Al Ayubi, 2020)

Teknologi informasi memiliki perkembangan yang sangat pesat dan meliputi berbagai bidang. Perkembangan tenologi dapat membawa dampak negative, tetapi juga dapat memberikan manfaat yang besar, tergantung bagaimana manusia meresponnya (Lintang Citra Christiani, 2021) Bidang Pendidikan merupakan salah satu bidang yang dipengaruhi oleh teknologi 
informasi. Baik dalam proses pembelajaran formal di sekolah maupun nonformal berupa pelatihan di luar sekolah ditujukan agar dapat meningkatkan kualitas proses (Erpidawati, 2021). Tenologi Informasi dan Komunikasi telah berkembang di semua bidang, oleh karena itu penggunaan terhadap perangkat teknologi komunikasi perlu di ajarkan pada semua tingkatan satuan Pendidikan (Yusri Ikhwani, 2015)

Pada era perkembangan zaman di saat ini, terkhususnya bagi kemajuan ilmu pengetahuan dan teknologi membuat berbagai macam bidang pekerjaan juga membutuhkan sumber daya manusia yang sudah bisa menguasai teknologi tersebut. Salah satunya yaitu dengan penguasaan terhadap berbagai jenis Microsoft (Nurmida Catherine Sitompul, 2021), Para Pengajar juga dituntun untuk selalu melakukan inovasi dalam pembelajaran.

Sumber daya Manusia dalam lingkup SMTPI JEMAAT sebagian besar memiliki semangat untuk belajar dan berusaha sehingga selalu menjadi baik dalam dunia Pendidikan, metode pembelajaran adalah metode yang meningkatkan keterampilan berpikir (Hanipah, 2017), Sistem Pedidikan yang baik akan mampu mengasilkan Sumber Daya Manusia (SDM) yang berkualitas, kompoten, dan professional dalam bidangnya serta memiliki kemandirian sebagai modal untuk bersaing dengan dunia luar (Dwi Safitaria, 2020).

Microsoft Power Point Merupakan salah satu Aplikasi yang dapat digunakan dalam mengembangkan kreatifitas dan meningkatkan Pengetahuan pada para pelajar (Ardiansah, 2019), Microsoft Power Point juga menjadi salah satu media yang dapat digunakan untuk menyampaikan materi berupa tulisan, gambar, foto, jenis tulisan, fitur hyperlink, audio , video dan animasi (Nurhidayati, 2019). Dengan diberikannya materi serta pelatihan Microsoft Power Point, maka Tujuan untuk meningkatkan Prestasi dan Kreatifitas SDM dapat terjawab dan menjadi lebih efektif dan bermanfaat serta sudah siap untuk masuk kedalam dunia persaingan pendidikan, selain pelatihan juga harus ditunjang dengan kegiatan yang berkelanjutan (Putri, 2018).

\section{METODE}

Persiapan Pengabdian Masyarakat Mandiri di SMTPI Bethesda adalah sebagai berikut :

1. Persiapan Kegiatan PKM di SMTPI Bethesda

2. Melakukan Koordinasi dengan Mitra Penyelenggara yaitu Ketua SMTPI Bethesda sebagai penanggung jawab dari kegiatan tersebut

3. Melakukan Survei lokasi PKM

4. Melalukan sosialisasi terhadap materi yang akan di sampaikan kepada Guru - Guru sekolah Minggu.

5. Menentukan jadwal kegiatan selama 2 hari

6. Menentukan Jumlah Peserta yang akan dijadikan sebagai objek.

A. Pelaksanaan

Pelaksanaan kegiatan Pengabdian Kepada Masyarakat mempertimbankan beberapa hal salah satunya tentang karakter setiap murid SMTPI Bethesda yang pada saat ini difokuskan pada tingkatan Remaja yang merupakan siswa/I SMA kelas I sampai Kelas III dengan sekolah yang berbeda beda. Maka dari itu, pendekatan kajian yang ada sebagai berikut :

1. Tingkat Motivasi Belajar computer untuk Murid SMTPI Tersebut masih rendah dan tidak didukung oleh fasilitas yang memadai

2. Dibutuhkan metode yang baik dalam meningkatkan kembali daya Tarik siswa-siswi.

3. Dibutuhkan metode yang baik agar setiap peserta bisa menggali kreatifitasnya dalam mendesain ppt yang menarik dan mampu mempresentasikannya. 


\section{HASIL DAN PEMBAHASAN}

Kegiatan pelaksanaan Pengabdian kepada Masyarakat di SMTPI Bethesda dilakukan selama 2 hari. Proses kegiatan kepada Masyarakat ini berjalan sesuai dengan jadwal yang telah disepakati bersama sehingga keberadaan selama kegiatan di lapangan tidak mengganggu proses kegiatan tersebut. Adapun kegiatan di lapangan sebagai berikut.

Tabel 1. Data Peserta Kegiatan PKM

\begin{tabular}{cccc}
\hline \multirow{2}{*}{ No } & \multirow{2}{*}{ Nama } & \multicolumn{2}{c}{ Data Kehadiran } \\
& & Hari Pertama & Hari Kedua \\
\hline 1 & Allan & V & V \\
2 & Esha & V & V \\
3 & Illy & V & V \\
4 & Peiter & V & V \\
5 & Livan & & \\
$\ldots$. & & V & V \\
45 & Gio & V & V \\
46 & Ugi & V & V \\
47 & Deydra & V & V \\
48 & Desly & V & V \\
49 & Ella & V & V \\
50 & Mey & & \\
\hline
\end{tabular}

Kegiatan hari pertama :

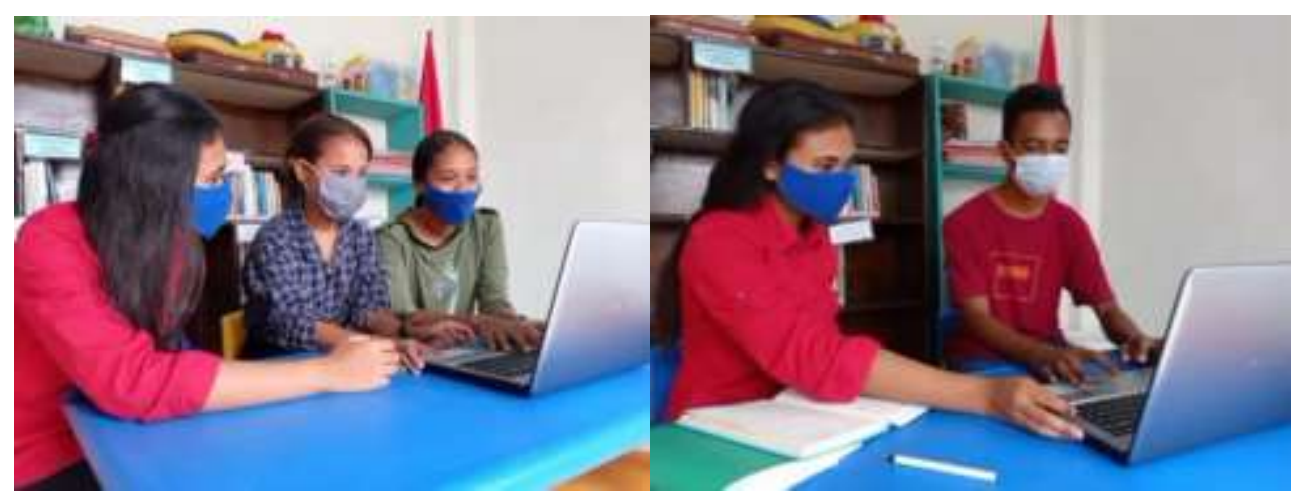

Gambar 1. Kegiatan Hari Pertama

Kegiatan pada hari pertama pada Sabtu, 27 Maret 2021 Pada Pukul 09.30 - 18.00 WIT, pada kegiatan hari pertama diikuti oleh 50 Peserta dengan materi awal yaitu pengenalan Aplikasi Power Point, pengenalan tools-tools dan fungsi yang tersedia pada aplikasi Power Point tersebut dengan tujuan agar peserta dapat memahami sebelum mendalami aplikasi tersebut. Setelah proses pengenalan selesai maka peserta diberikan kesempatan untuk menggunakan fasilitas yang disediakan untuk menggunakan aplikasi tersebut. Materi yang disampaikan dapat dilihat pada beberapa gambar berikut.

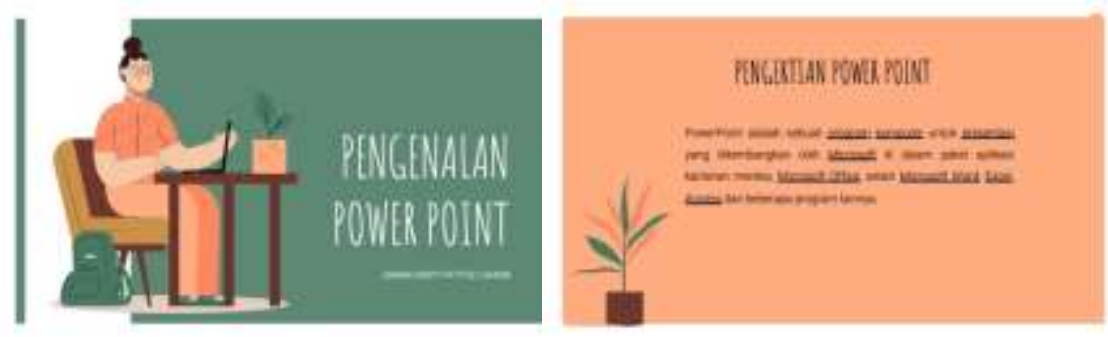

Gambar 2. Materi PPT 
Kegiatan hari kedua :

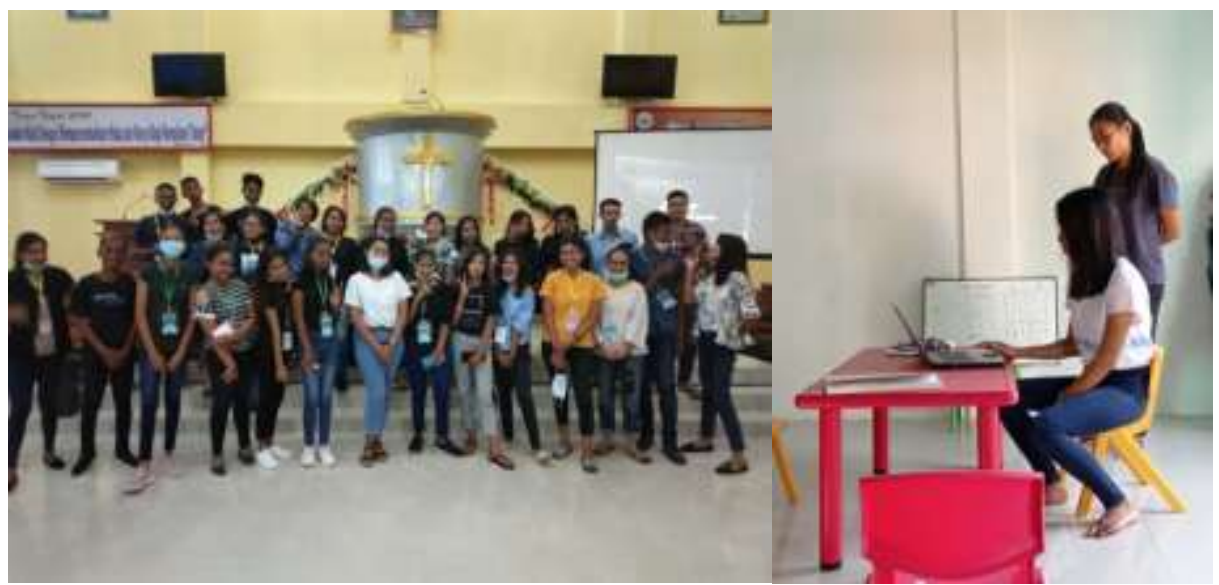

Gambar 3. Kegiatan Hari kedua

Kegiatan pada hari kedua pada Minggu, 28 Maret 2021 Pada Pukul 13.00 - 18.00 WIT, pada kegiatan hari kedua diikuti oleh 50 Peserta. Kegiatan hari kedua dilakukan lebih variative sehingga peserta dibagi menjadi 12 kelompok dan masing - masing kelompok diberikan tema untuk menyiapkan materi pada PPT dan selanjutnya dilakukan proses presentasi dari setiap kelompok.

Hasil Capaian Kemampuan pemahaman peserta dalam memahami materi dan Penggunaan Aplikasi Power Point ditunjukan dalam sebuah data sebagai berikut :

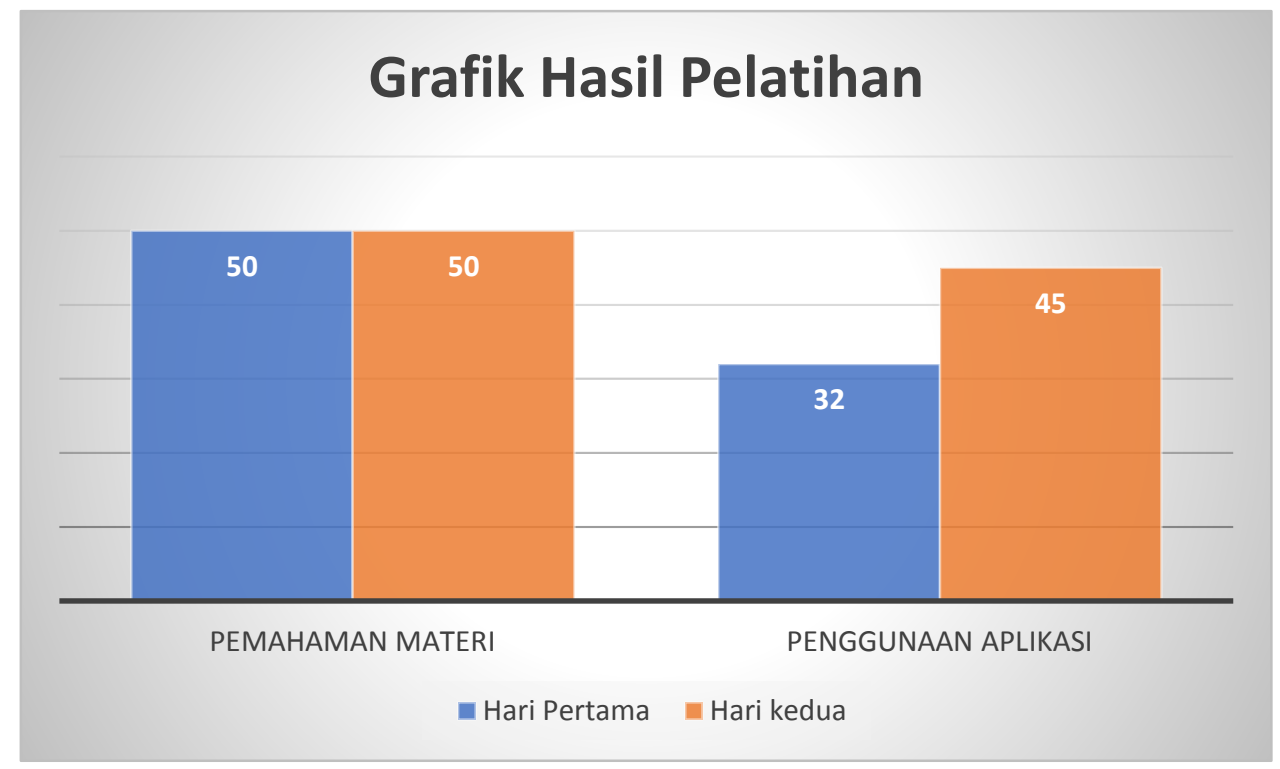

Gambar 4. Grafik Hasil Pelatihan PPT pada SMTPI Bethesda.

Hasil data diatas menunjukan bahwa kemampuan peserta di SMTPI Bethesda dalam memahami, menggunakan dan merepresentasikannya secara baik dan aktif tergolong sudah baik dan terdapat peningkatan dan sangat diharapkan agar peserta tetap diberikan dukungan dan perhatian khusus sehingga mampu untuk mengembangkan tingkat kreatifitasnya. 


\section{KESIMPULAN}

Hasil kegiatan Pengabdian Masyarakat dengan Judul "Peningkatakan Mutu Prestasi \& Minat Bakat SMTPI Bethesda Melalui Aplikasi Ms. Power Point (PPT)" menunjukan peningkatan terhadap pengetahuan dan kreatifitas para peserta. Dari aspek pengetahuan, diketahui bahwa peserta dapat memahami fungsi-fungsi yang tersedia pada Ms. Power Point (PPT) sehingga dapat dengan mudah menggunakan aplikasi tersebut. Kesimpulan yang terpenting adalah Peserta sudah mengenalnya dengan baik karena iti dari kegiatan ini adalah memperkenalkan Ms.Power Point kepada peserta sehingga dapat dikembangkan dan mengasah kreatifitas dari para peserta untuk persiapan dalam dunia Pendidikan.

\section{UCAPAN TERIMA KASIH}

Terimakasih Kepada Rektor Universitas Kristen Indonesia Maluku , Lembaga Penelitian Universitas Kristen Indonesia Maluku, Semua Pihak yang telah membantu dan bertanggung jawab, dan kepada Mitra SMTPI Bethesda.

\section{DAFTAR PUSTAKA}

Ardiansah, f. d. (2019). Pelatihan Pembuatan Media Pembelajaran Interaktif Berbasis Powerpoint Bagi Tenaga Pendidik Paud Himpaudi Kecamatan Gabek Kota Pangkalpinang. Jurnal Pengabdian Pada Masyarakat., 1-6.

Dwi Safitaria, H. A. (2020). Upaya Meningkatkan Motivasi dan hasil belajar siswa menggunakan model pembelajaran kooperatif tipe student teams achievement divisions (STAD) Pelajaran komputer \& Jaringan dasar X TKJ SMK AL ALIF BLORA. Joined Journal, 26-31.

Erpidawati, N. (2021). Pelatihan Pemanfaatan Teknologi Google Drive dan Blogs bagi pengawas sekolah dasar. DINAMISIA : Jurnal Pengabdian Kepada Masyarakat, 330 - 334.

Hanipah, S. F. (2017). The Effectiveness of Problem Based Learning and Project Based Learning Model to Improve Natural Science Study Outcomes. Innovation Journal of Curriculum and Educational Technology, 1-6.

Lintang Citra Christiani, P. N. (2021). Pengembangan Kemandirian Kelompok Difabel melalui pemanfaatan Pemasaran Digital di Kota Magelang. DINAMISIA : Jurnal Pengabdian Kepada Masyarakat, 276 - 286.

Muhamad Sholahudin Al Ayubi, R. I. (2020). Pengembangan Media Pembelajaran pada Mata Pelajaran Jaringan dan Dasar Komputer. Joined Journal, 32-39.

Nurhidayati, I. A. (2019). Pembuatan Media Pembelajaran Berbasis Powerpoint Dan Pemanfaatan Aplikasi Android Untuk Guru Bahasa Arab. Jurnal KARINOV

Putri, L. D., \& Soehardi, F. (2018). Pemberdayaan Mahasiswa Fakultas Teknik Dengan Program Kreatifitas Mahasiswa (PKM). Dinamisia: Jurnal Pengabdian Kepada Masyarakat, 2(2), 315321.

Nurmida Catherine Sitompul, R. I. (2021). Perancangan Blog Guru untuk Penyediaan Bahan Ajar di Era Pembelajaran Abad 21. DINAMISIA : Jurnal Pengabdian Kepada Masyarakat, 320 - 329.

Yusri Ikhwani, H. B. (2015). Pelatihan Aplikasi Microsoft Word 2013 pada SMP H.A. Hohansyah A Banjarmasin. Jurnal Al-Ikhlas, 11-14. 